\title{
Long-term trends in the relation between daytime and nighttime values of $f \circ \mathrm{F} 2$
}

\author{
A. D. Danilov \\ Institute of Applied Geophysics, Rostokinskaya 9, Moscow, 129128, Russia \\ Received: 10 May 2007 - Revised: 3 January 2008 - Accepted: 3 January 2008 - Published: 28 May 2008
}

\begin{abstract}
The data from the vertical ionospheric sounding for 12 stations over the world were analyzed to find the relation between the values of $f o \mathrm{~F} 2$ for 02:00 LT and 14:00 LT of the same day. It is found that, in general, there exists a negative correlation between $f o \mathrm{~F} 2(02)$ and $f o \mathrm{~F} 2(14)$. The value of the correlation coefficient $R(f o \mathrm{~F} 2)$ can be in some cases high enough and reach minus $0.7-0.8$. The value of $R(f o \mathrm{~F} 2)$ demonstrates a well pronounced seasonal variations, the highest negative values being observed at the equinox periods of the year. It is also found that $R(f o \mathrm{~F} 2)$ depends on geomagnetic activity: the magnitude of $R(f o \mathrm{~F} 2)$ is the highest for the choice of only magnetically quiet days $\left(A_{p}<6\right)$, decreasing with the increase of the limiting value of $A_{p}$. For a fixed limitation on $A_{p}$, the value of $R\left(f_{o} \mathrm{~F} 2\right)$ depends also on solar activity. Apparently, the effects found are related to thermospheric winds. Analysis of long series of the vertical sounding data shows that there is a long-term trend in $R\left(f_{o} \mathrm{~F} 2\right)$ with a statistically significant increase in the $R(f o \mathrm{~F} 2)$ magnitude after about 1980 . Similar analysis is performed for the $f o \mathrm{~F} 2(02) / f o \mathrm{~F} 2(14)$ ratio itself. The ratio also demonstrates a systematic trend after 1980. Both trends are interpreted in terms of long-term changes in thermospheric circulation.
\end{abstract}

Keywords. Ionosphere (Ionosphere-atmosphere interactions; Mid-latitude ionosphere)

\section{Introduction}

The problem of long-term changes (trends) in the ionosphere is an object of a close attention of specialists in various scientific groups (see the summarizing paper by Lastovicka et al., 2006). In spite of many efforts applied, there is still no common opinion either on the values of the trends in F2-

Correspondence to: A. D. Danilov

(adanilov99@mail.ru) region parameters, or on their origin (for details see Lastovicka et al., 2006). Various mechanisms are considered including greenhouse gases increase, long-term changes in geomagnetic activity, and anthropogenic changes in the thermosphere. All of these mechanisms may impact the F2-layer parameters via both, changes in photochemical (composition, temperature) or dynamical (circulation, vertical drift) parameters of the thermosphere.

Till now all the studies of trends in the F2 region were aimed at the analysis of long-term behavior either of $f o \mathrm{~F} 2$ or $h m \mathrm{~F} 2$. The main goal of this paper is to try to take a look at the trends in the relation between the nighttime and daytime values of $f o \mathrm{~F} 2$. The reason for such an attempt is that $f o \mathrm{~F} 2$ in the daytime and at night is governed by different processes: photochemistry and composition changes dominate in the daytime, whereas dynamical processes (vertical drift induced mainly by the horizontal circulation) govern the nighttime values of $f o \mathrm{~F} 2$.

Vanina-Dart and Danilov (2006) were the first to draw attention to the fact that there is a significant negative correlation between the nighttime and daytime values of $f o \mathrm{~F} 2$ for the same day. Danilov (2006) described the phenomenon in detail. It was found that the correlation coefficient $R(f o \mathrm{~F} 2)$ between the nighttime and daytime values of $f o \mathrm{~F} 2$ for the same day is negative and can by the magnitude reach values of 0.8-0.9. Analyzing the data of a dozen of ionospheric stations, Danilov (2006) studied the main features of the effect. The detailed description of all the features of the phenomenon is out of the scope of this paper and we refer the reader to the above paper. Here we briefly describe only the main points important for the problem of deriving long-term trends in $R(f o \mathrm{~F} 2)$.

The values of $f o \mathrm{~F} 2$ for 14:00 LT and 02:00 LT of the same day were taken as representatives of the daytime and nighttime values for the analysis. The correlation coefficient $R(f o \mathrm{~F} 2)$ was calculated over a three-month running interval with a step of one month. This means that, for example,

Published by Copernicus Publications on behalf of the European Geosciences Union. 
Table 1. List of ionospheric stations mentioned in the paper.

\begin{tabular}{lccclcccc}
\hline Station & \multicolumn{3}{c}{$\begin{array}{c}\text { Coordinates } \\
\text { Geogr. Geom. }\end{array}$} & Station & \multicolumn{3}{c}{$\begin{array}{c}\text { Coordinates } \\
\text { Geogr. Geom. }\end{array}$} \\
\hline Dourbes & $50 \mathrm{~N}$ & $5 \mathrm{E}$ & $52 \mathrm{~N}$ & Leningrad & $60 \mathrm{~N}$ & $31 \mathrm{E}$ & $56 \mathrm{~N}$ \\
Hobart & $43 \mathrm{~S}$ & $147 \mathrm{E}$ & $51 \mathrm{~S}$ & Moscow & $56 \mathrm{~N}$ & $37 \mathrm{E}$ & $51 \mathrm{~N}$ \\
Juliusruh & $55 \mathrm{~N}$ & $14 \mathrm{E}$ & $54 \mathrm{~N}$ & Poitiers & $47 \mathrm{~N}$ & $0 \mathrm{E}$ & $49 \mathrm{~N}$ \\
Gorky & $56 \mathrm{~N}$ & $44 \mathrm{E}$ & $59 \mathrm{~N}$ & Slough & $52 \mathrm{~N}$ & $0 \mathrm{E}$ & $54 \mathrm{~N}$ \\
Kaliningrad & $55 \mathrm{~N}$ & $21 \mathrm{E}$ & $53 \mathrm{~N}$ & Tomsk & $57 \mathrm{~N}$ & $85 \mathrm{E}$ & $46 \mathrm{~N}$ \\
\hline
\end{tabular}

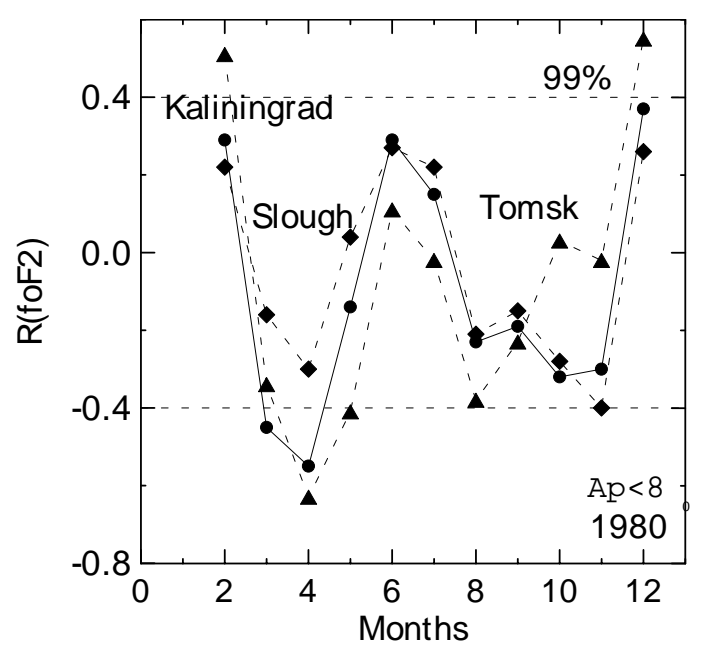

Fig. 1. Variations in $R\left(f_{o} \mathrm{~F} 2\right)$ over the year for 3 stations: Kaliningrad (circles), Slough(diamonds), and Tomsk (triangles). Horizontal dashed lines show the values of $R(f o \mathrm{~F} 2)$ needed to provide a $99 \%$ confidence level according to the Fisher's F parameter test.

the point for April in Fig. 1 corresponds to the correlation between the nighttime and daytime values of $f o \mathrm{~F} 2$ calculated for the March-May period. The calculations were performed for different levels of magnetic activity $\left(A_{p}<6,12,16,20\right.$, 30 , and 40). In each case only the days with $A_{p}$ lower than the particular value were taken for the calculation of $R(f o \mathrm{~F} 2)$. The list of stations mentioned in this paper is presented in Table 1 .

Figure 1 shows the seasonal behavior of $R(f o \mathrm{~F} 2)$ for three stations for $A_{p}<8$. First, one can see a strong similarity in the $R(f o \mathrm{~F} 2)$ behavior with time for all three stations. This fact increases the reliability of the effect, because three absolutely independent sets of data provide the same picture.

The main feature of Fig. 1 is the presence of two pronounced maxima in the magnitude of $R(f o \mathrm{~F} 2)$ in spring and fall. The absolute value of $R(f o \mathrm{~F} 2)$ in spring for Tomsk and Kaliningrad stations reaches about 0.6 and exceeds the value providing the $99 \%$ significance by the Fisher F parameter test (Pollard, 1977). The fall maximum in the $R(f o \mathrm{~F} 2)$ magnitude is lower, $R(f o \mathrm{~F} 2)$ being about -02 to -03 . Principally the same picture was obtained for all stations and all limitations over $A_{p}$ considered. In some cases the fall maximum was of the same magnitude (or even slightly higher) then the spring

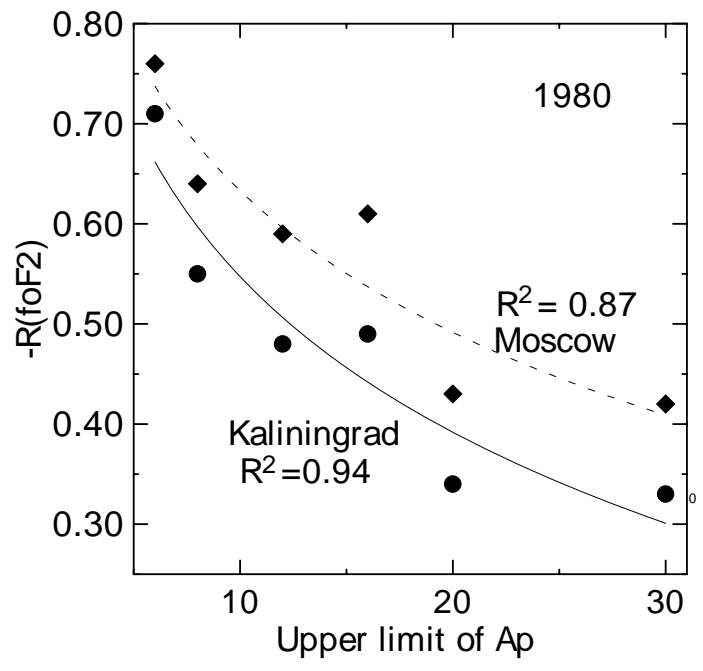

Fig. 2. Variations of $R(f o \mathrm{~F} 2)$ with the limiting value of the $A_{p}$ index for two stations.

one, but in the majority of cases the spring maximum dominated. Some sort of a maximum (but with positive values of $R(f o \mathrm{~F} 2))$ is seen in Fig. 1 at the solstices. However, the summer maximum is low and of low statistical significance. As for the winter maximum, the magnitude of $R(f o \mathrm{~F} 2)$ can in some cases reach $0.4-0.5$, but never be as high as that for the equinox maxima (0.7-0.8). No special analysis has been performed for the solstice maxima.

\section{Trends in the $R(f o \mathrm{~F} 2)$ value}

To characterize each year for the particular station and limitation in magnetic activity we took the maximum negative value of $R(f o \mathrm{~F} 2)$ regardless the season it was obtained. For the sake of comparison we considered also taking only the spring (March-April) values and found that principally the results are the same, but the statistics is certainly better in the former case.

The dependence of $R(f o \mathrm{~F} 2)$ for two stations on geomagnetic activity (on the limiting value of $A_{p}, A_{p}(\mathrm{lim})$ ) for 1980 is shown in Fig. 2. The magnitude of $R(f o \mathrm{~F} 2)$ is seen to increase with the decrease in $A_{p}(\mathrm{lim})$. In other words, the quieter the days we choose, the better is pronounced the negative correlation between $f o \mathrm{~F} 2(02)$ and $f o \mathrm{~F} 2(14)$. If only very quiet days $\left(A_{p}<6\right)$ are chosen for the calculation of $R(f o \mathrm{~F} 2)$, the magnitude of the latter exceeds 0.7 , whereas at $A_{p}<30$ it is $0.35-0.40$. The approximation by a logarithmic function is shown by lines in Fig. 2 . The $R^{2}$ values show the determination coefficients for the approximation lines.

Figures similar to Figs. 1 and 2 were calculated for all the stations and thresholds in $A_{p}$ considered. The principal picture is the same with inevitable random scatter of the data. 
To look for possible long-term trends in $R(f o \mathrm{~F} 2)$ we had to remove the $R(f o \mathrm{~F} 2)$ dependence on solar activity. Such dependence exists (see Fig. 3 for Slough) though with the scatter of points, part of which may be due to the trends we are looking for. To remove the solar activity effects, we applied a simple method used in many publications on trends in the F2 region (see Bremer, 1998). We drew a regression line (solid line in Fig. 3) and for each point took the deviation from it: $\Delta R(f o \mathrm{~F} 2)=R(f o \mathrm{~F} 2)(\mathrm{obs})-R(f o \mathrm{~F} 2)(\mathrm{reg}), R(f o \mathrm{~F} 2)(\mathrm{obs})$ and $R(f o \mathrm{~F} 2)(\mathrm{reg})$ being the values of $R(f o \mathrm{~F} 2)$ obtained by the method described above and corresponding to the regression line, respectively.

The time behavior of $\Delta R(f o \mathrm{~F} 2)$ for Hobart and Dourbes stations is shown in Fig. 4. One can see that there is a scatter of the $\Delta R(f o \mathrm{~F} 2)$ values before 1979 with poorly pronounced variation with time. After 1979 the picture looks different: there is a pronounced $\left(R^{2}=0.52\right.$ and 0.41$)$ decrease in the $\Delta R(f o \mathrm{~F} 2)$ value with time. The decrease is statistically significant at the $99 \%$ confidence level according to the Fisher $\mathrm{F}$ parameter test. The decrease in $\Delta R(f o \mathrm{~F} 2)$ means an increase in the magnitude of $R(f o \mathrm{~F} 2)$.

Similar pictures were obtained for other stations analyzed. Examples of $\Delta R(f o \mathrm{~F} 2)$ variations with time for Juliusruh and Slough are presented in Fig. 5 and for Kaliningrad and Moscow in Fig. 6. One can see that the determination coefficient $R^{2}$ after about 1980 is high enough and provides the confidence level of $99 \%$ according to the Fisher F parameter test.

The boundary between the two regions with different $\Delta R(f o \mathrm{~F} 2)$ behavior only slightly differs for all the stations considered and corresponds to 1978-1982. Thus, we see a systematic change at all stations: after about 1980 the negative correlation coefficient between the daytime and nighttime values of $f_{o} \mathrm{~F} 2$ increase by the magnitude.

Some indications of the existence of periods of growth and decline in $R\left(f_{o} \mathrm{~F} 2\right)$ may be found also before 1980. Figure 7 shows the 132-month smoothed values of the $A_{p}$ index according to Mikhailov et al. (2002) (top panel) and values of $\Delta R\left(f_{o} \mathrm{~F} 2\right)$ for Slough station smoothed in the same way (see also Fig. 4). One can see that the behavior of $\Delta R(f o \mathrm{~F} 2)$ repeats the behavior of $A_{p}$ (smooth) with a delay of about 3 years. That is exactly what Mikhailov et al. (2002) found for the behavior of $h m \mathrm{~F} 2$ at Slough station.

Figure 8 shows the behavior of $\Delta R(f o \mathrm{~F} 2)$ for Gorky, Juliusruh, and Moscow stations. No smoothing has been applied. Just the points were approximated by a linear regression for 1970-1980 and for years before 1970. The only aim of this action is to show that there is a similarity in the time behavior of $\Delta R(f o \mathrm{~F} 2)$ for these three stations with the time behavior of the smoothed values of $A_{p}$. Comparing Fig. 8 with the top panel of Fig. 7, one can see that even without the 132-month smoothing (as in the case of Slough) the time behavior of $\Delta R(f o \mathrm{~F} 2)$ with considerable scatter shows the same features as the time behavior of $A_{p}$ (smooth). The latter fact suggests that the long-term variations in $R(f o \mathrm{~F} 2)$ (at

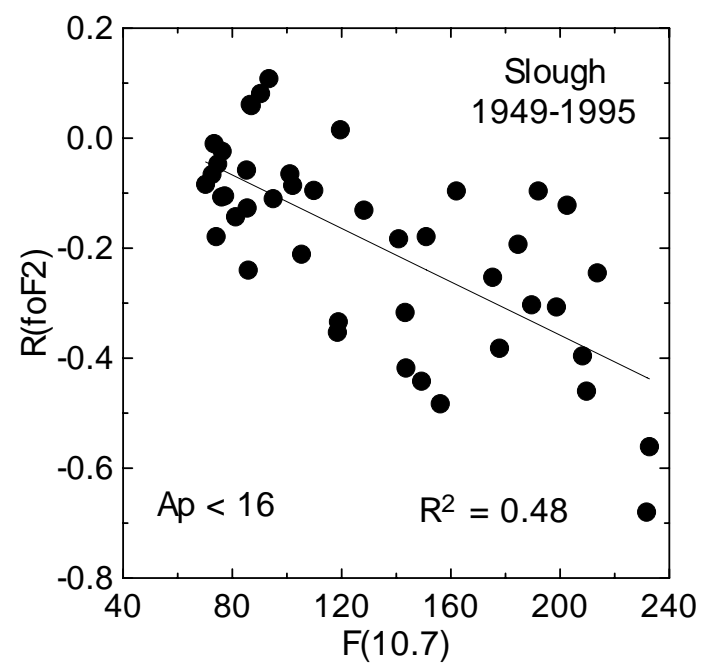

Fig. 3. The $R(f o \mathrm{~F} 2)$ dependence on the solar activity index $\mathrm{F}(10.7)$ for Slough.

least, before 1980) may be caused by the long-term variations in magnetic activity as was suggested by Mikhailov et al. (2002) for $f o \mathrm{~F} 2$ variations.

\section{Trends in the foF2(02)/foF2(14) value}

The second step of the analysis was to consider the behavior of the ratio of the critical frequencies $f o \mathrm{~F} 2(02) / f o \mathrm{~F} 2(14)$ itself.

The annual variations in $f o \mathrm{~F} 2(02) / f o \mathrm{~F} 2(14)$ presented nothing unexpected with a slight maximum in the ratio in June-July. So the average of the $f o \mathrm{~F} 2(02) / f o \mathrm{~F} 2(14)$ values for these two months and for January-February was taken for each year in further searches for long-term trends.

As to the dependence on geomagnetic activity, it appeared to be quite different from that for $R(f o \mathrm{~F} 2)$. Figure 9 shows variations with $A_{p}(\mathrm{lim})$ of $R(f o \mathrm{~F} 2)$ and $f o \mathrm{~F} 2(02) / f o \mathrm{~F} 2(14)$ for Slough for the fall period. One can see that the behavior of $R(f o \mathrm{~F} 2)$ is the same as shown in Fig. 2 for Kaliningrad and Moscow (the magnitude of $R(f o \mathrm{~F} 2)$ increases with a decrease of $A_{p}(\mathrm{lim})$ ), whereas $f o \mathrm{~F} 2(02) / f o \mathrm{~F} 2(14)$ shows no significant dependence on $A_{p}(\mathrm{lim})$.

The different behavior of $R(f o \mathrm{~F} 2)$ and $f o \mathrm{~F} 2(02) / f o \mathrm{~F} 2(14)$ shown in Fig. 9 is easily understood in the scope of the concept considered. Variations in intensity and even direction of the meridional wind (which are especially frequent around equinoxes) would change the $f o \mathrm{~F} 2(02) / f o \mathrm{~F} 2(14)$ ratio in both directions, but the average value for the days with the chosen $A_{p}(\mathrm{lim})$ over three months would not vary considerably. At the same time, this variation would lead to an increase in the $R(f o \mathrm{~F} 2)$ correlation coefficient (as it is described below in Sect. 4). 

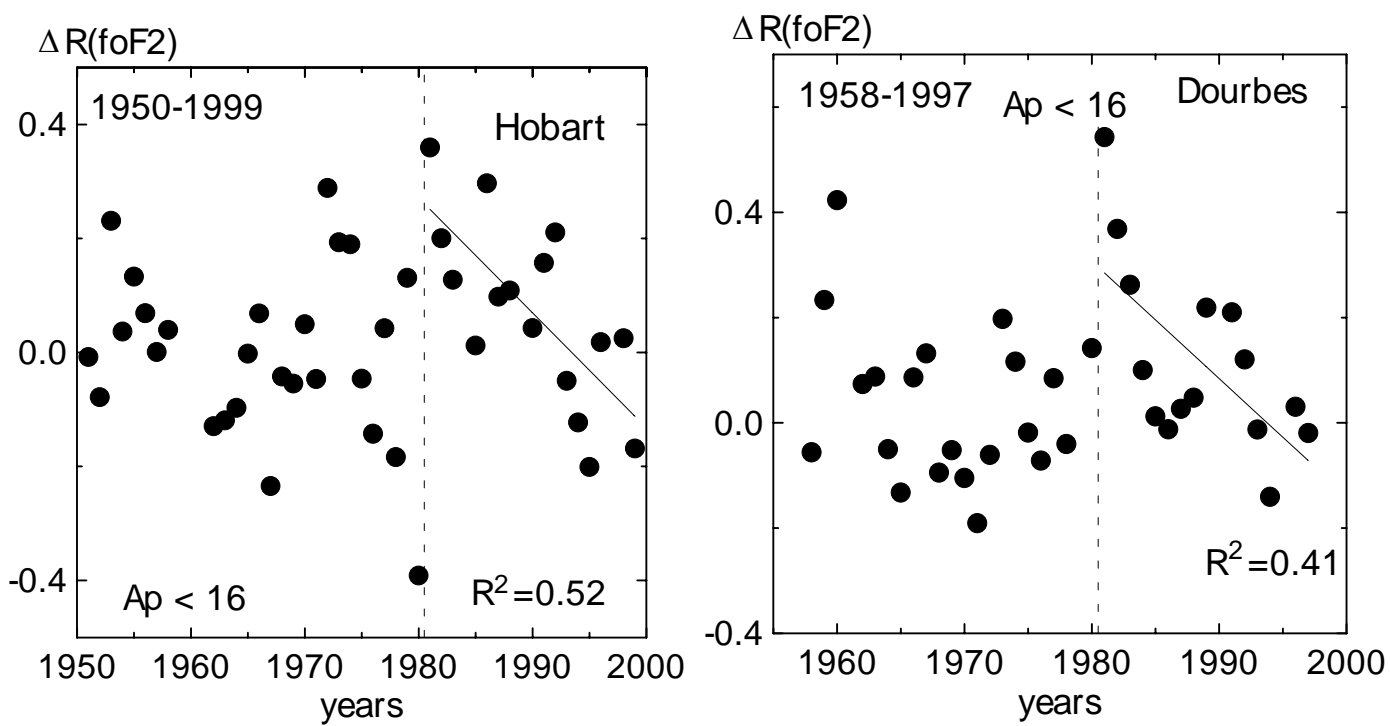

Fig. 4. Variations with time of the $\Delta R(f o \mathrm{~F} 2)$ for Hobart and Dourbes.
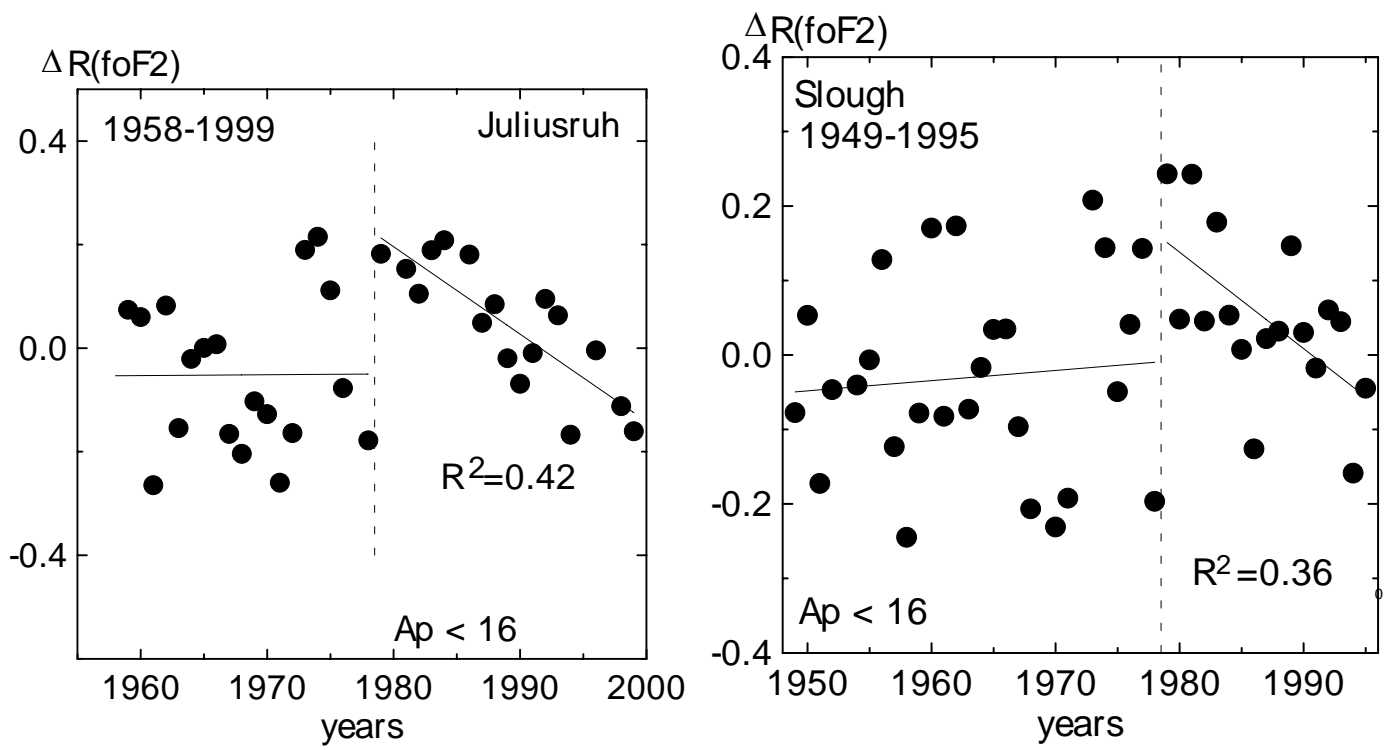

Fig. 5. Variations with time of the $\Delta R(f o \mathrm{~F} 2)$ for Juliusruh and Slough.

In the same way as $R(f o \mathrm{~F} 2)$, the $f_{o} \mathrm{~F} 2(02) / f_{o} \mathrm{~F} 2(14)$ value depends on solar activity. Figure 10 shows this dependence for Moscow for $A_{p}<30$. One can see that the dependence of $f o \mathrm{~F} 2(02) / f o \mathrm{~F} 2(14)$ on solar activity index $\mathrm{F}(10.7)$ is much better pronounced and statistically significant than that for $R(f o \mathrm{~F} 2)$ (see above Fig. 3).

In the same way as it has been done above for $R(f o \mathrm{~F} 2)$, to get rid of the dependence on solar activity, the $\Delta f o(02) / f o(14)$ value has been found as the deviation of each particular point in Fig. 10 from the approximation line.
A detailed analysis of the $\Delta f o \mathrm{~F} 2(02) / f o \mathrm{~F} 2(14)$ behavior was presented by Danilov (2008) ${ }^{1}$. A detailed description of the results is outside the frame of this paper. We note only that analyzing the data of 42 ionospheric stations, it was found that principally the situation is similar to that with $\Delta R(f o$ F2) (see Figs. 4-6): after about 1980 the value of $\Delta f o(02) / f o(14)$ demonstrate a systematic variation with

\footnotetext{
${ }^{1}$ Danilov, A. D.: Time and spatial variations of the $f_{o}$ F2(night)/foF2(day) values, Paper presented at the IRI/COST Workshop (Prague, July 2007), Adv. Space Res., submitted, 2008.
} 

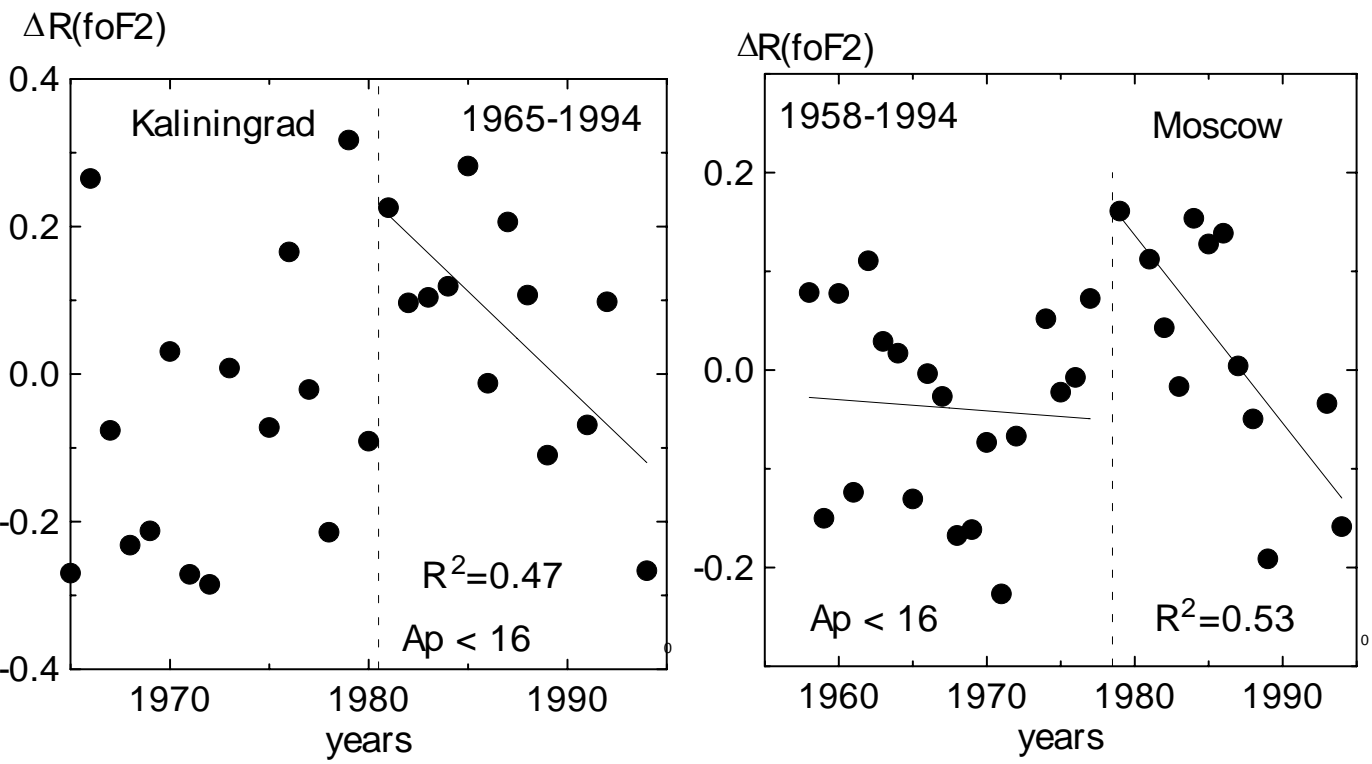

Fig. 6. Variations with time of $\Delta R(f o \mathrm{~F} 2)$ for Kaliningrad and Moscow $\left(A_{p}<16\right)$.

time (a decrease or increase) which is statistically significant at the 95-99\% confidence level according to the Fisher's F parameter test. Figures 11, 12, and 13 show examples of the time behavior of the $\Delta f o \mathrm{~F} 2(02) / f_{o} \mathrm{~F} 2(14)$ value for some stations. Danilov $(2008)^{1}$ found also that the sign of the $\Delta f o \mathrm{~F} 2(02) / f o \mathrm{~F} 2(14)$ changes after about 1980 is related to the magnetic inclination and declination of the station. That made it possible to postulate that the observed effect is caused by systematic changes in the zonal wind in the thermosphere (Danilov, 2008 ${ }^{1}$ ).

The analysis shows that, unlike in Figs. 7 and 8, no systematic behavior resembling the $A_{p} 132$ long-term behavior can be found in the $\Delta f o \mathrm{~F} 2(02) / f o \mathrm{~F} 2(14)$ behavior before about 1980.

This difference in the behavior of $R(f o \mathrm{~F} 2)$ and $f_{o} \mathrm{~F} 2(02) / f_{o} \mathrm{~F} 2(14)$ with time before 1980 is understandable if one takes into account the result illustrated by Fig. 9 above. The latter shows that $R\left(f_{o} \mathrm{~F} 2\right)$ is very sensitive to changes in geomagnetic activity, whereas $f_{o} \mathrm{~F} 2(02) / f_{o} \mathrm{~F} 2(14)$ is not. Respectively, there is a pronounced signature of magnetic activity long-term variations in $R(f o \mathrm{~F} 2)$ behavior during the decades preceding 1980, whereas there is no such signature in the $f_{o} \mathrm{~F} 2(02) / f_{o} \mathrm{~F} 2(14)$ behavior.

The trend in the correlation coefficient $R(f o \mathrm{~F} 2)$ after about 1980 , considered above in this paper, presumably indicate systematic changes in the meridional wind in the thermosphere. The $\Delta f_{o} \mathrm{~F} 2(02) / f_{o} \mathrm{~F} 2(14)$ behavior after 1980 was shown by Danilov (2008) ${ }^{1}$ to indicate to systematic change in the zonal wind. So one can assume that there is a change in the dynamical regime of the thermosphere. At the moment, one cannot say what causes this change. The latter may be
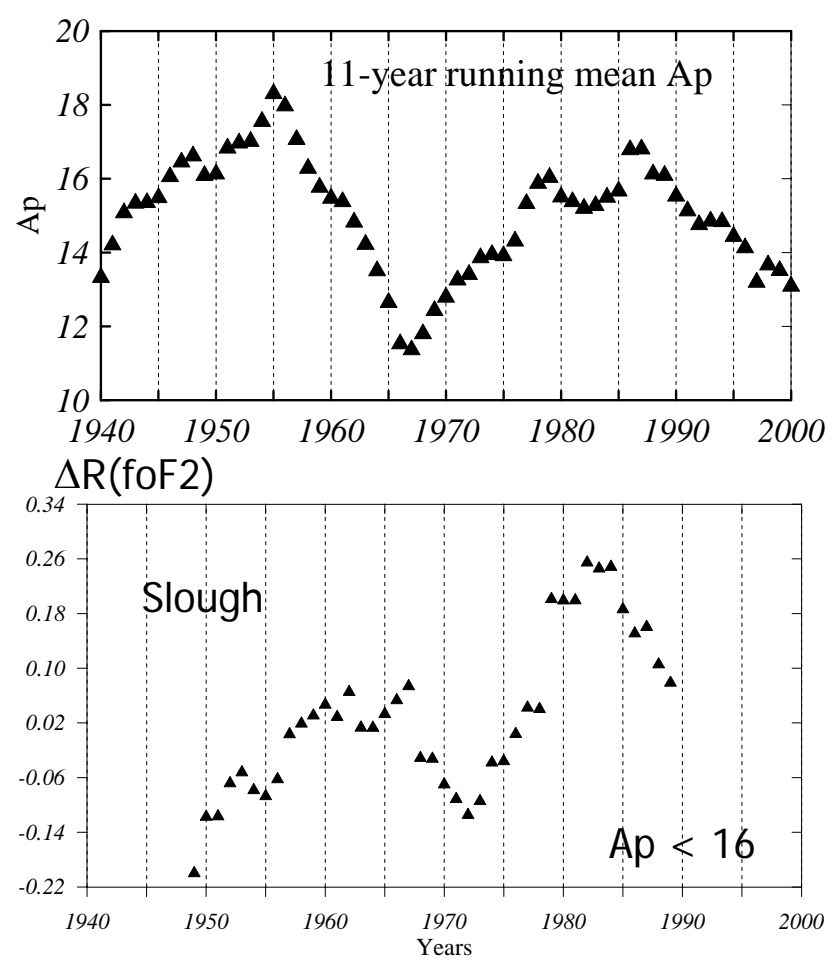

Fig. 7. Comparison of the 132-month smoothed values of $A_{p}$ and $\Delta R(f o \mathrm{~F} 2)$ for Slough.

an indirect manifestation of the long-term changes in magnetic activity, or a consequence of anthropogenic changes in the atmosphere, first of all, the increase in the greenhouse 


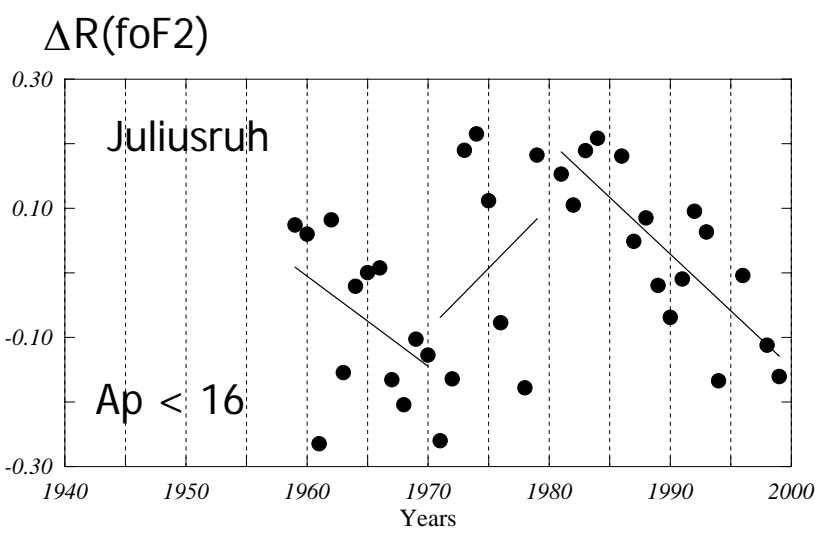

$\Delta R($ foF 2$)$
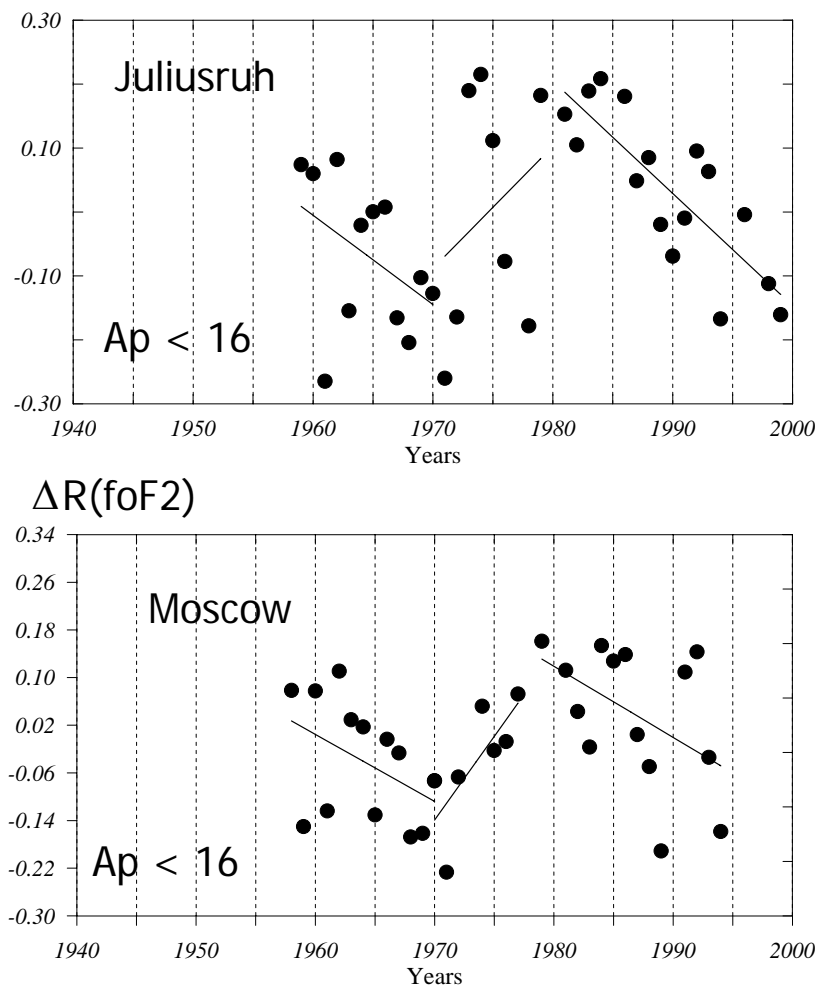

Fig. 8. Time behavior of $\Delta R(f o \mathrm{~F} 2)$ for Gorky, Juliusruh, and Moscow.

gas amount. In the majority of papers, the impact of this increase on the middle and upper atmosphere is considered via the changes in neutral temperature. However, it seems to be inevitable that such changes (different at different heights) should lead to changes in the global circulation pattern, including the meridional and zonal winds at thermospheric heights.

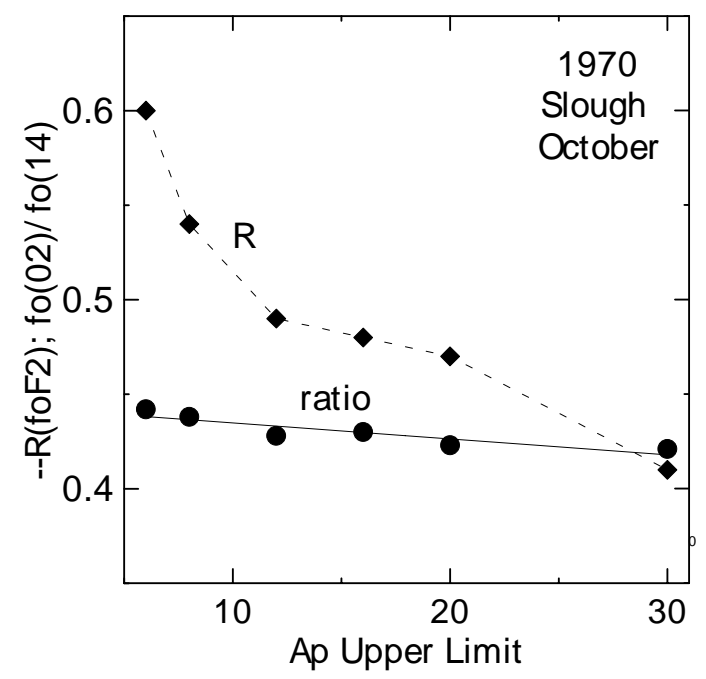

Fig. 9. Variations with the limiting value of $A_{p}$ in $R(f o \mathrm{~F} 2)$ and $f_{o} \mathrm{~F} 2(02) / f_{o} \mathrm{~F} 2(14)$ for the fall period of 1970 at Slough.

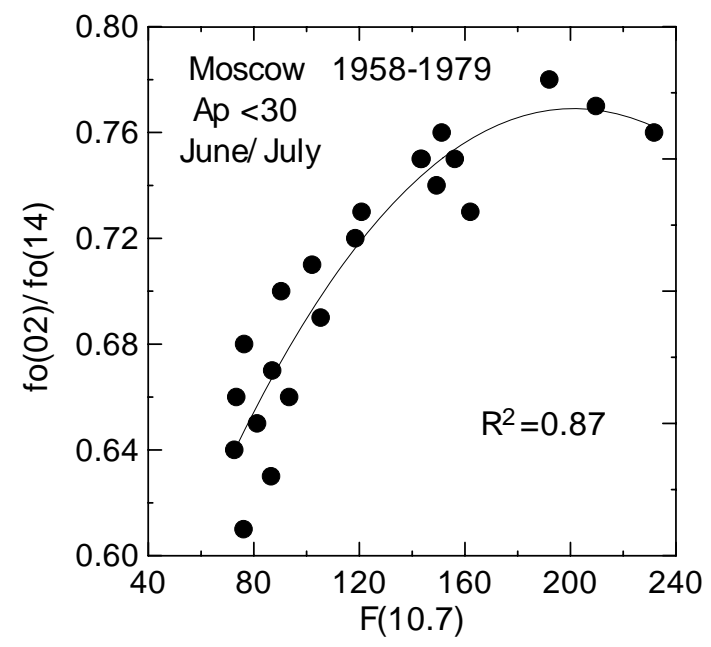

Fig. 10. The $f o(02) / f o(14)$ dependence on the solar activity index $\mathrm{F}(10.7)$ for Moscow. Solid line shows the approximation of the points by a 3rd degree polynomial.

\section{Conclusions}

The analysis of long-term trends in the relation between the daytime and nighttime values of $f_{o} \mathrm{~F} 2$ is performed in two ways. Consideration of the correlation coefficient $R(f o \mathrm{~F} 2)$ between $f o \mathrm{~F} 2(02)$ and $f_{o} \mathrm{~F} 2(14)$ (the values of $f o \mathrm{~F} 2$ for 02:00 LT and 14:00 LT) shows that $R(f o F 2)$ is negative in spring and fall and has a maximum in magnitude (most often in spring) reaching $0.8-0.85$. The coefficient is very sensitive to magnetic activity: with the $A_{p}$ threshold of the days chosen for its calculation, the magnitude of $R(f o \mathrm{~F} 2)$ increases. For all the ionospheric stations considered the value 

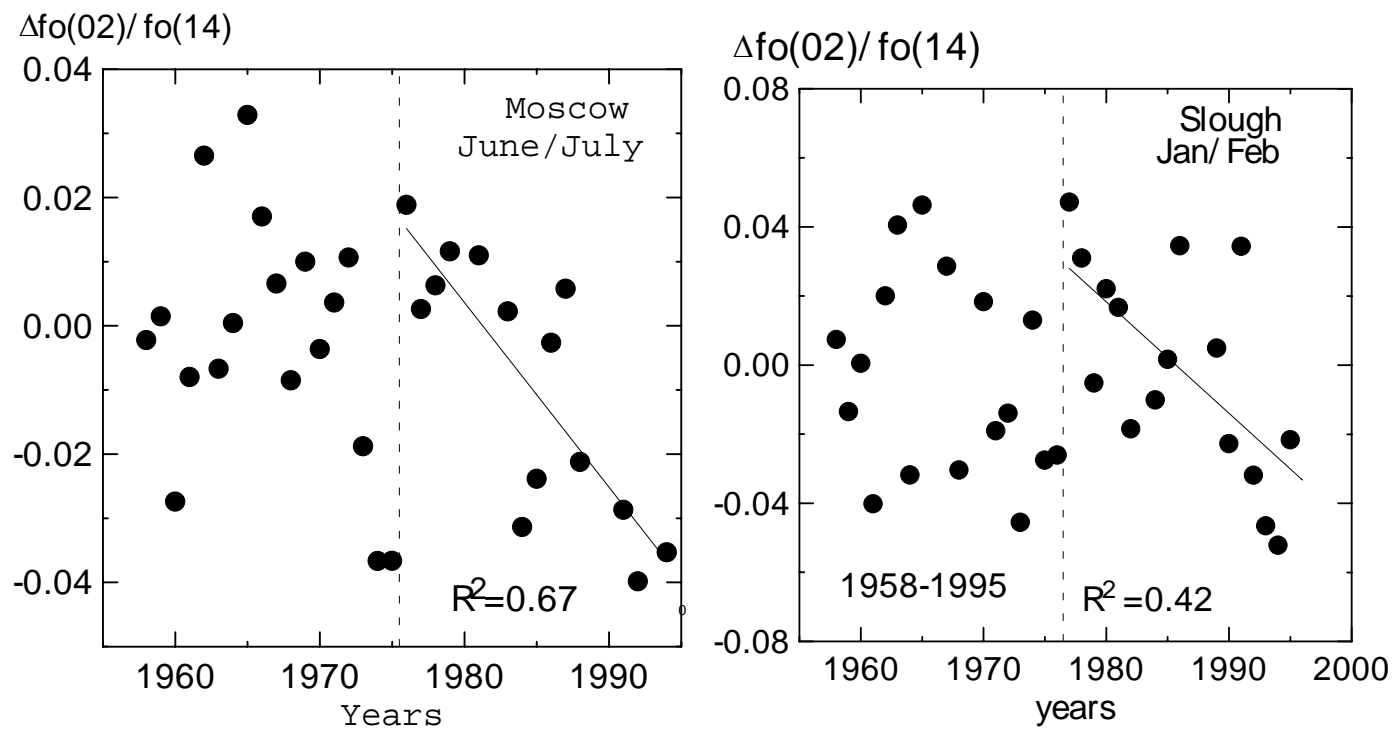

Fig. 11. Time behavior of $\Delta f o \mathrm{~F} 2(02) / f o \mathrm{~F} 2(14)$ for Moscow and Slough.
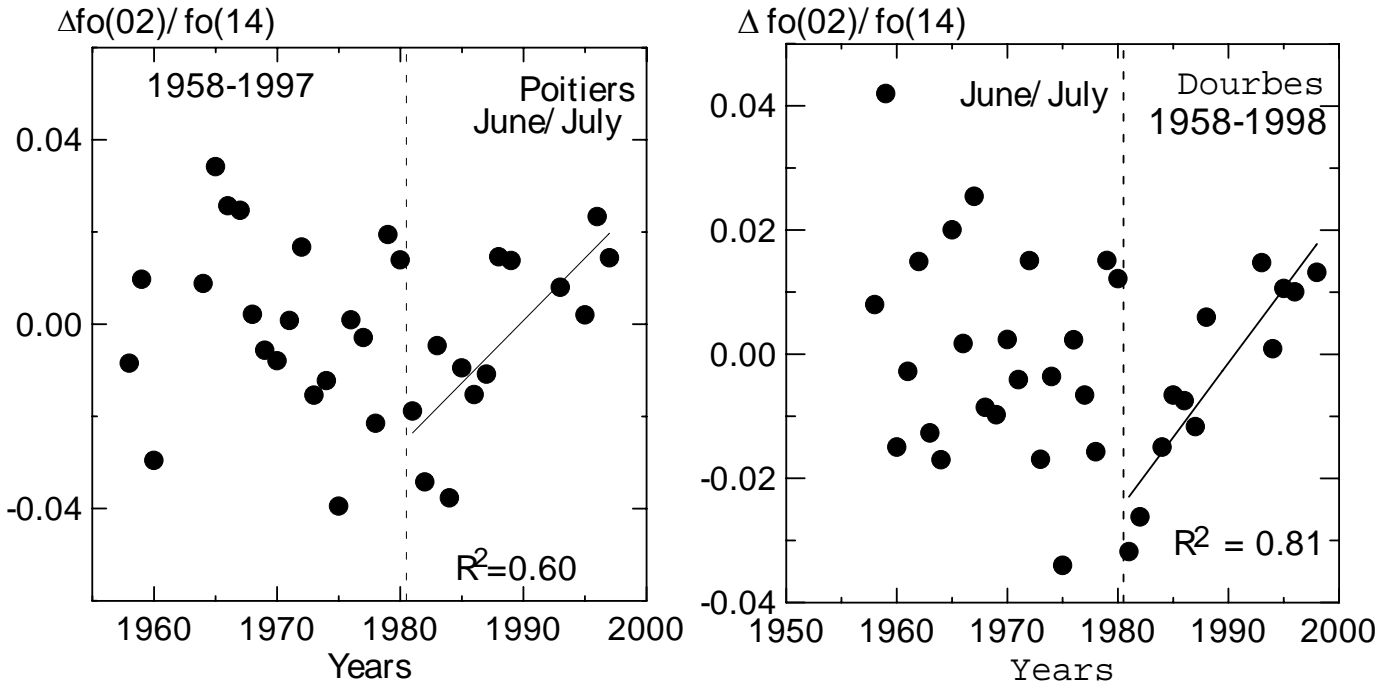

Fig. 12. Time behavior of $\Delta f o \mathrm{~F} 2(02) / f o \mathrm{~F} 2(14)$ for Poitiers and Dourbes.

of $R(f o \mathrm{~F} 2)$ demonstrates the same feature: after about 1980 the magnitude of negative $R(f o \mathrm{~F} 2)$ increases.

Looking for an explanation of the existence of the negative correlation coefficient and the features of its behavior described above, we offer the following proposal. The daytime value of $\mathrm{NmF} 2$ (i.e. $f o \mathrm{~F} 2$ ) increases with an intensification of the poleward meridional wind because the latter increases values of the atomic oxygen concentration. The same wind shifts the F2-layer maximum along the magnetic field lines down to lower altitudes into the region of higher recombination and so leads to a decrease in the nighttime values of $N m \mathrm{~F} 2$. The equatorward meridional circulation leads to the opposite effect for both, the daytime and nighttime values of $N m F 2$. Thus, changes in the meridional wind should lead to opposite changes in the daytime and nighttime values of $f_{o} \mathrm{~F} 2$, providing negative correlation between these values.

The above-described concept explains, first of all, the seasonal behavior of $R(f o \mathrm{~F} 2)$ (see Fig. 1). Actually, the strongest changes in the meridional wind (including the wind direction reversal) happen in the spring and fall periods during the circulation reversals. It should lead to the highest magnitudes of the negative correlation in these periods. That is exactly what one sees in Fig. 1. 


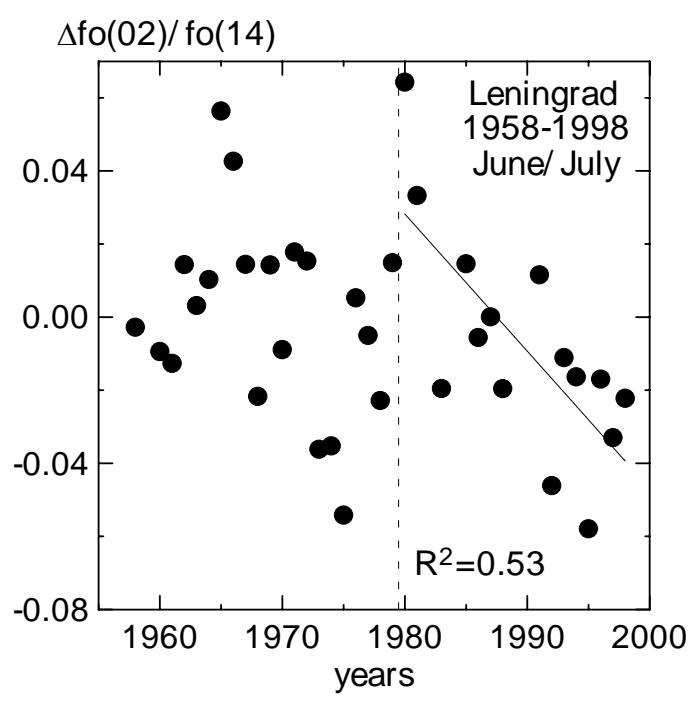

Fig. 13. Time behavior of $\Delta f o(02) / f o(14)$ for Leningrad and Tomsk.

The dependence of $R(f o \mathrm{~F} 2)$ on the magnetic activity threshold (see Fig. 2) is also understandable. The effect of the changes in the meridional wind intensity and direction should be the more pronounced the quieter the geomagnetic situation. In geomagnetically disturbed conditions, the simple scheme described is distorted by the influence of the heating in the auroral oval, which counteracts poleward wind, leading to changes not only in the meridional circulation, but in the composition and temperature of the thermospheric gas at F2-region heights, as well.

In the scope of the concept described, the systematic increase of the magnitude of $R(f o \mathrm{~F} 2)$ after about 1980 suggests that since this date there was a systematic intensification of the meridional circulation.

The behavior of $R(f o \mathrm{~F} 2)$ before 1980 demonstrates some similarity with the behavior of the smoothed values of $A_{p}$ used by Mikhailov et al. (2002) to derive trends in $f o F 2$. This similarity leads to the conclusion that the changes in the circulation may be due to the long-term magnetic activity effects.

The same analysis was performed for the $f o \mathrm{~F} 2(02) / f o \mathrm{~F} 2(14)$ ratio itself. The ratio demonstrates no pronounced dependence on the choice of magnetically quiet days. After about 1980 a systematic change in the $f o \mathrm{~F} 2(02) / f o \mathrm{~F} 2(14)$ value is found for all stations considered (Danilov, 2008 ${ }^{1}$ ). These changes are presumably related to changes in the zonal thermospheric wind. Jointly, the analysis of the data on $R(f o \mathrm{~F} 2)$ and $f o \mathrm{~F} 2(02) / f o \mathrm{~F} 2(14)$ indicate changes in the thermospheric circulation at F-region heights after about 1980. The cause of these changes is not clear yet. It may be an indirect effect of the long-term changes in magnetic activity, or a manifestation of long-term changes in the dynamical regime of the upper atmosphere resulting from anthropogenic impact.

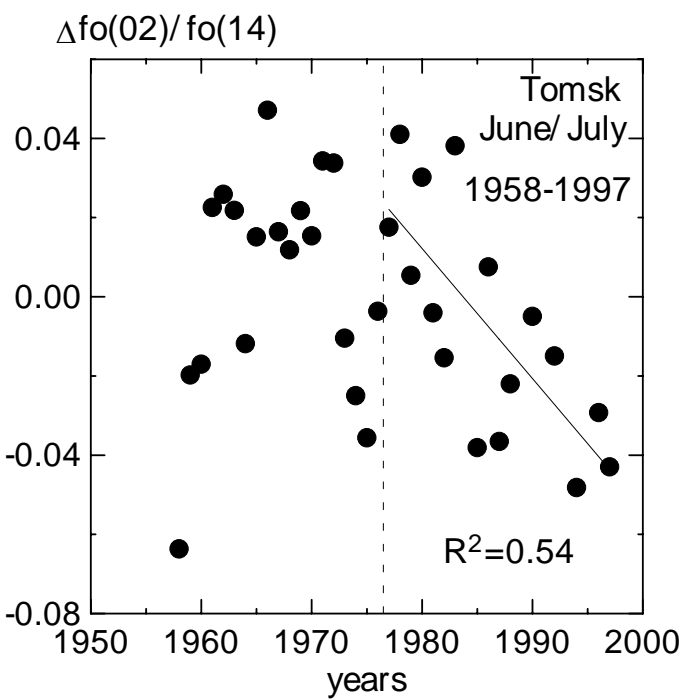

Acknowledgements. The author thanks A. V. Mikhailov for creation of computer programs required and for a fruitful discussion of the results and a Reviewer, P. Wilkinson for vary valuable comments and corrections of the language. The work was supported by the Russian Foundation for Basic Research (project No. 04-05-64832).

Topical Editor M. Pinnock thanks P. Wilkinson and another anonymous referee for their help in evaluating this paper.

\section{References}

Bremer, J.: Trends in the ionospheric E and F regions over Europe, Ann. Geophys., 16, 986-996, 1998, http://www.ann-geophys.net/16/986/1998/.

Danilov, A. D.: Relation between daytime and night-time values of the critical frequency foF2, Int. J. Geomagn. Aeron., 6(3), GI3003, doi:10.1029/2005GI000129, 2006.

Laštovička, J., Ulich, T., Bremer, J., Elias, A. G., Ortiz de Adler, N., Jara, V., Abarca del Rio, R., Floppiano, A. J., Ovalle, E., and Danilov, A. D.: Long-term trends in $f_{o} \mathrm{~F} 2$ : a comparison of various methods, J. Atmos. Solar-Terr. Phys., 68, 1854-1870, 2006.

Mikhailov, A. V., Marin, D., Leshchinskaya, T. Yu., and Herraiz, M.: A revised approach to the $f o \mathrm{~F} 2$ long-term trends analysis, Ann. Geophys., 20, 1663-1675, 2002, http://www.ann-geophys.net/20/1663/2002/.

Pollard, J. H.: A Handbook of Numerical and Statistical Techniques, Cambridge University Press, Cambridge, 1977.

Vanina-Dart, L. B. and Danilov, A. D.: Relation between the daytime and nighttime critical frequencies of the F2 region, Geomagn. Aeron., 46(2), 219-223, 2006 (in Russian). 